\title{
Effect of Chemical Composition, Anatomy and Cell Wall Structure on Tensile Properties of Bamboo Fiber
}

\author{
Shamsun Nahar ${ }^{1,2, *}$, and Mahbub Hasan ${ }^{1}$ \\ 1 Department of Materials and Metallurgical Engineering, Bangladesh University of Engineering and \\ Technology, Dhaka 1000, Bangladesh \\ 2 Bangladesh College of Leather Engineering and Technology, Dhaka, Bangladesh \\ *E-mail: shamshilpi@yahoo.com (Corresponding author)
}

\begin{abstract}
Ligno-cellulosic fiber is an effective reinforcement as an alternative for manmade fiber in composite, while keeping the weight of the composite lower. In this paper, the assessment of bamboo fiber for composite was conducted with the determination of strength, Young's modulus and strain to failure using single fiber tensile test. The mean strength and standard deviation were calculated. Furthermore, a correction method assessed the real fiber elongation from the measured clamp displacement. Chemical analysis of bamboo fiber was conducted and the fiber surface and sclerenchyma cell wall in block was anatomically observed under SEM. Chemical analysis and surface analysis results showed that bamboo fiber is a technical fiber with parenchyma and sclerenchyma cell containing high amount of $\alpha$-cellulose $(50.23 \%)$ and holocellulose $(67.08 \%)$. The fibers constitute the sclerenchymatous tissue and occur in the internodes as caps of vascular bundles or isolated strands. The fibers are grouped in bundles and sheaths around the vessels. For that reason bamboo fiber has high tensile strength $(882 \pm 307 \mathrm{MPa})$. Young's modulus for $5,10,15,25$ and $35 \mathrm{~mm}$ span length were found to be $10.41 \pm 4.52,17.90 \pm$ $7.67,23.67 \pm 8.66,29.49 \pm 4.78,33.52 \pm 11.04 \mathrm{GPa}$ respectively. After correction the Young's modulus was found to be $33.86 \mathrm{GPa}$. Strain to failure of bamboo fiber was found to be $3.90 \%$. Thus it can be concluded that this procedure seems to be useful for strong bamboo fiber to produce more reliable results.
\end{abstract}

Keywords: Tensile strength, $\alpha$-cellulose, sclerenchyma cell, SEM.

ENGINEERING JOURNAL Volume 17 Issue 1

Received 30 July 2012

Accepted 23 September 2012

Published 1 January 2013

Online at http://www.engj.org/

DOI:10.4186/ej.2013.17.1.61 


\section{Introduction}

Polymer matrix composites, such as carbon or glass fiber reinforced plastics have been widely used in industry since they have high strength and modulus $[1,2]$. In the context of challenging environmental issues and a global energy crisis, bio-based materials are attracting increasing levels of research interest, from both academia and industry, because of their numerous advantages: renewable resource usage, low cost, biodegradability and so on [3-5]. Hemp, flax, sisal, jute etc have been identified as attractive candidates for the reinforcement of thermoplastic polymers. They are cheap, abundant and renewable, and have good specific properties due to their low densities [6-10]. Recently natural fiber reinforced polymers were used mainly in the construction and automotive industries. These markets are rapidly expanding. Other applications requiring high mechanical performance are envisaged, in order to enhance and highlight the properties of this plant-based resource. Naturally, the strength and load-bearing capabilities of composites are directly dependent on the mechanical properties of their constituents (fibers and matrices), their microstructure and their interfacial bond strength. Bamboo fibers represent one of the most attractive natural fibers because of their availability and excellent mechanical properties. Nevertheless, only few efforts have been carried out globally to extract long bamboo fibers from the culm particularly because of difficulties in extracting long high quality, undamaged fibers. Many researchers have given attraction on bamboo fiber composites [11-14]. Bamboo is composed of lignin, $\alpha$-cellulose, hemicelluloses etc. It has high tensile strength compared to that of mild steel, high strength to weight ratio, high specific load bearing capacity but requires less energy for production. Bamboo has fastest growth rate among the commonly available natural fibers. Cellulose constituent is oriented along the length of the fiber giving flexural strength and rigidity in that direction. Bamboo is also one of the most underutilized natural resources available abundantly in Southeast Asian countries [15, 16]. It consists of $60 \%$ cellulose and $32 \%$ lignin. Its $2-10^{\circ}$ microfibril angles are responsible for making it useful as reinforcement. Bamboo is orthotropic, which means it has particular mechanical properties in three principle directions: longitudinal, radial, and tangential [17]. Bamboo plants have culm, which is characterized by nodes. The internodes are surrounded by large cavity, called lucuna, axially oriented. Culm wall is composed of parenchyma cell, ground tissue, in which vascular bundles are embedded. There sclerenchyma fibers sheaths around the vascular bundles determine mechanical properties. Parenchymateous tissues can pass loads when force is applied [18]. For these reasons bamboo fiber is often regarded as natural glass fiber. In this study possible value of Bangladeshi bamboo was assessed. Single bamboo fibers were selected in this study. Tensile properties and their standard deviation were calculated experimentally. A theoretical correction was carried out to determine the real elongation of the fiber when only one the registered displacement is available.

\section{Experimental Method}

\subsection{Materials}

Bamboo fiber was extracted from culms of bamboo plants. The fiber was extracted by steam exploration out of the Bambosa vulgaris species, which is available in Bangladesh. Diameter of the fiber used for tensile test was taken from SEM. Before tensile test, fiber was visually selected in order to verify the absence of defects along the length of the fiber.

\subsection{Chemical Analysis}

In order to determine chemical composition (holocellulose, alpha-cellulose, Klason lignin, hot water extractives and ash) of bamboo, the internodes of each height were cut into small strips with razor blade. The strips were small enough to be placed to ground in a Wiley mill. The material was then placed in a shaker with sieves to pass through a no. 40 mesh sieve $(425-\mu \mathrm{m})$, yet retained on a no. 60 mesh sieve (250$\mu \mathrm{m})$. The resulting material was then placed in glass jars for chemical analysis. All tests were conducted using ASTM standards [19-24]. 


\subsection{Morphological Study}

The anatomy of bamboo culm and cell was observed using scanning electron microscope (XL 30 Philips, Netherland). The samples were made conductive by applying a gold coating using sputtering technique. Thin gold coating caused the electrons to interact with the inner atomic shells of the sample.

\subsection{Tensile Test}

Tensile properties was carried out using an Instron universal testing machine (Model no3369) by varying span lengths $(5 \mathrm{~mm}, 10 \mathrm{~mm}, 15 \mathrm{~mm}, 25 \mathrm{~mm}$ and $35 \mathrm{~mm}$ ) [25]. Sample preparation set up is shown in Fig 1 . The cross-head speed and load cell used were $1 \mathrm{~mm} / \mathrm{min}$ and $200 \mathrm{~N}$ respectively. Samples which had broken near the edge of the clamps were excluded from the analysis. The isolated fibers were conditioned at $20 \pm$ $2^{\circ} \mathrm{C}$ and $65 \pm 2 \%$ relative humidity before temporarily fixed on the paper frame with adhesive tape. A droplet of glue was applied on the centre of both sides of the hole along the length of card. The testing was then carried out as follows:

1) Subjecting the prepared samples to SEM, characterizing the surface of the test pieces and measuring the diameter;

2) Subjecting the samples to tensile strength test.

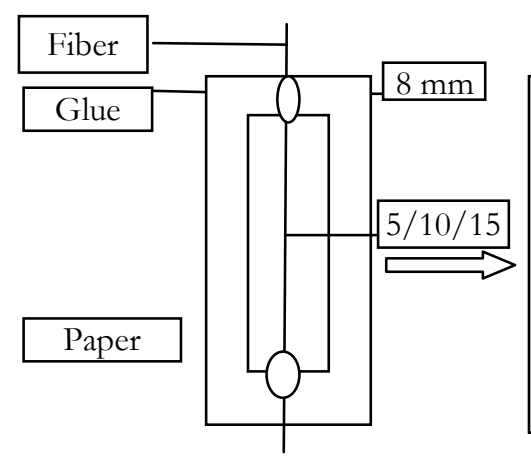

(a)

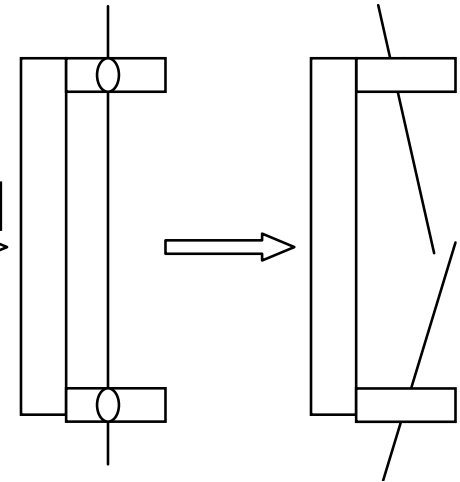

(b)

(c)

Fig.1. Set-up of single fiber testing: (a) specimen mount, (b) test specimen on the paper frame, and (c) broken fiber.

The tensile strength was calculated using following formulas

$$
\text { Tensile Strength } \quad \sigma=\frac{F_{\max }}{A}
$$

where $F_{\max }$ is maximum force and $A$ is cross sectional area.

Young's Modulus and strain to failure was measured from the stress-strain curve. During tensile test, some slippage portions always occur. Large span length minimizes the slippage portion in comparison to smaller ones. Thus Young's modulus found was higher for larger which was not desired. So correction was required for Young's modulus values. Young's modulus was corrected by using the following steps:

$$
\frac{\Delta l_{\text {total }}}{\text { Test length }}=\frac{\Delta l_{\text {fiber }}}{\text { Test length }}+\frac{\Delta l_{\text {nonfiber }}}{\text { Test length }}
$$

where $\Delta l_{\text {total }}$ is the measured displacement of the clamps, $\Delta l_{\text {fiber }}$ is the elongation of the fiber and $\Delta l_{\text {nonfiber }}$ is the displacement caused by slippage and test set up compliance.

A correction process was adopted to determine the non fiber displacement. The fiber displacement $\Delta h_{\text {total }}$ was measured and at a certain stress in the linear part of the stress-strain curve was calculated. $\left(\Delta l_{\text {fiber }}\right.$ /test length) was calculated by dividing the same chosen stress by the estimated the e-modulus for an 
infinity long test length, in other word the extrapolated modulus from an Young's modulus in function of $(1 /$ span length $)$ curve at $(1 /$ span length $)=0$.

$$
\frac{\Delta l_{\text {non fiber }}}{\text { test length }}=\frac{\alpha F}{\text { test length }}=\frac{\sigma A \alpha}{\text { test length }}
$$

where $F$ is the load put on the fiber, $A$ is the cross-sectional area and $\sigma$ is the stress (in the linear portion of the stress strain curve), and $\alpha$ is the factor that estimates the influence of slippage and the test setup compliance. So for every tested fiber $\alpha$ can be calculated:

$$
\alpha_{i}=\frac{\Delta l_{\mathrm{total}, i}-\Delta l_{\mathrm{fiber}, i}}{F_{i}}
$$

All $\alpha$-values were plotted as function of span length and by linear regression, an estimated of the $\alpha$-value for each test length can be determined $\left(\alpha_{\text {test length }}\right)$ for each type of fiber. With this estimated value for $\alpha$ the corrected strain can be calculated:

$$
\text { Corrected Strain }=\frac{\Delta l_{\text {fiber }, i}}{\text { test length }}=\frac{\Delta l_{\text {total }, i}}{\text { test length }}-\frac{\alpha_{\text {test length }} F_{i}}{\text { test length }}
$$

Young's modulus was finally determined by taking the slop from the corrected stress-strain curve.

\section{Results and Discussion}

\subsection{Chemical Analysis}

The results of bamboo chemistry testing are listed in Table 1. Li worked on Phyllostachys pubescens bamboo and found 5.14\% hot water solubility, $22.11 \%$ lignin, $70.84 \%$ holocellulose, $47.30 \% \alpha$-cellulose, $1.94 \%$ ash [26]. Ghoshal et al. worked on bamboo fiber and found $60 \%$ cellulose and $32 \%$ lignin [16]. During present chemical analysis, alpha cellulose was found to be $50.23 \pm 0.18 \%$ indicating that homopolysacsride consists of $\beta$-D-glucopyranose linked together by $\beta$-1-4-linkage. Each cellulose monomer contained three hydroxyl groups that were able to form hydrogen bond for crystalline packing governing the tensile properties of

\begin{tabular}{|c|c|c|c|c|c|c|}
\hline Sample & $\begin{array}{l}\text { Hot Water } \\
\text { Soluble }\end{array}$ & Lignin & Holocellulose & $\alpha$-cellulose & Hemicellulose & Ash \\
\hline Bamboo & $5.07 \pm 0.0612 .33 \pm 0.56$ & $23.91 \pm 0.58$ & $67.08 \pm 0.17$ & $50.23 \pm 0.18$ & $16.85 \pm 0.09$ & $1.38 \pm 0.05$ \\
\hline
\end{tabular}
cellulose of bamboo [27-30].

Table 1. Chemical analysis results of bamboo fiber.

\subsection{Morphological Study}

In present study anatomy and cell wall was observed. Surface of bamboo fiber and cross-sectional area of bamboo block samples were observed under scanning electron microscope. Figures 2(a) and 2(b) represent the surface of bamboo fiber and cross-sectional area of bamboo block respectively. The inner layer is wrapped by sclerenchyma cells. In lacuna, elements in bamboo are easily permeable. The structure of a bamboo culm transverse section characterized by numerous vascular bundles embedded in the sclerenchyma tissue and parenchymatous ground tissue. The parenchyma cells are mostly thin-walled and connected to each other by numerous simple pits. Pits are located predominantly on the longitudinal walls. But the sclerenchyma cells are thick-walled. Sclerenchyma generally forms packages of fibers below vascular bundles and around the vascular bundle. Sclerenchyma surrounding the first cycle of peripheral vascular bundles are not interrupted by interfascicular parenchyma. 


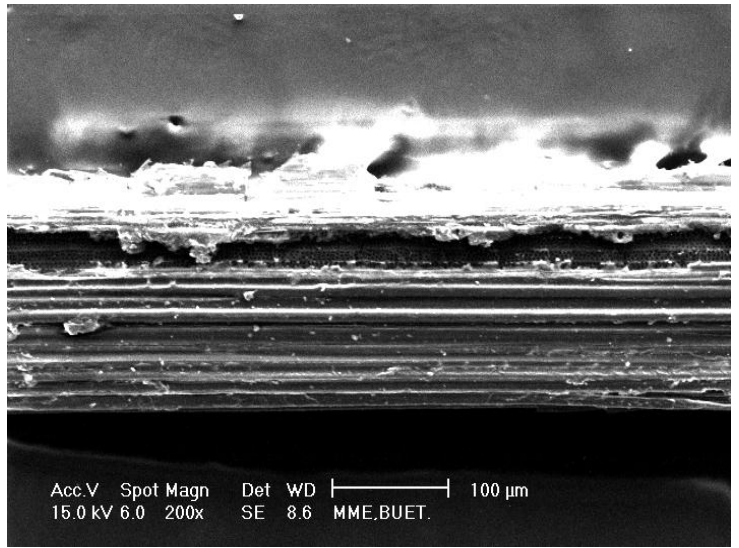

(a)

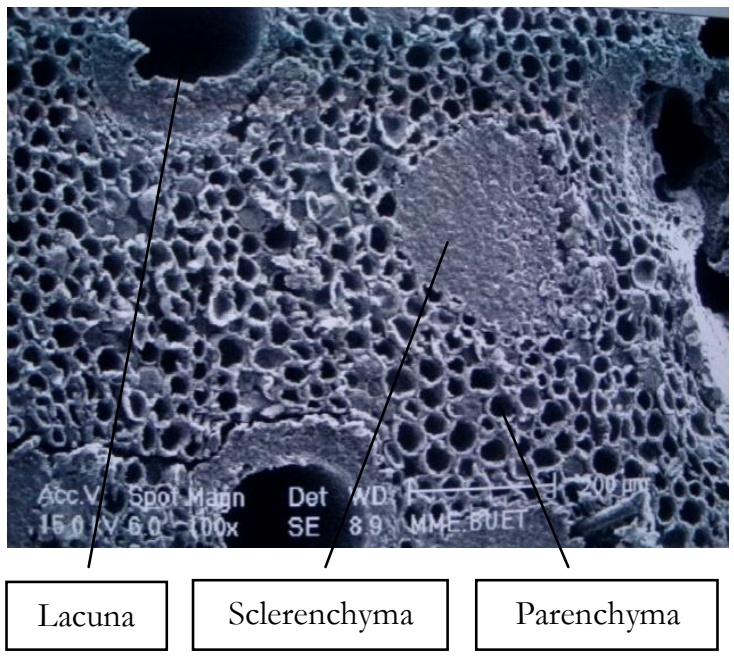

(b)

Fig. 2. SEM of (a) cell wall and (b) cross-sectional area of bamboo block.

\subsection{Tensile Properties}

The tensile strength of bamboo single fiber is shown in Fig. 3. Tensile strength decreased with an increase in fiber span length. This is because the fiber of larger span length has much larger surface area having more flaws and surface defects, which make the chance of failure larger. The corrected and uncorrected Young's modulus values are shown in Fig. 4. Uncorrected Young's values increased with an increase in span length. This may be due to slippage and test setup. The slippery portion is higher for smaller span length compared to higher span length. The uncorrected extrapolated Young's modulus for infinitely long fiber was 35.2 GPa. Strain to failure against span length is shown in Fig. 5. With increasing fiber span length, the strain to failure decreased due to more weaknesses and earlier break.

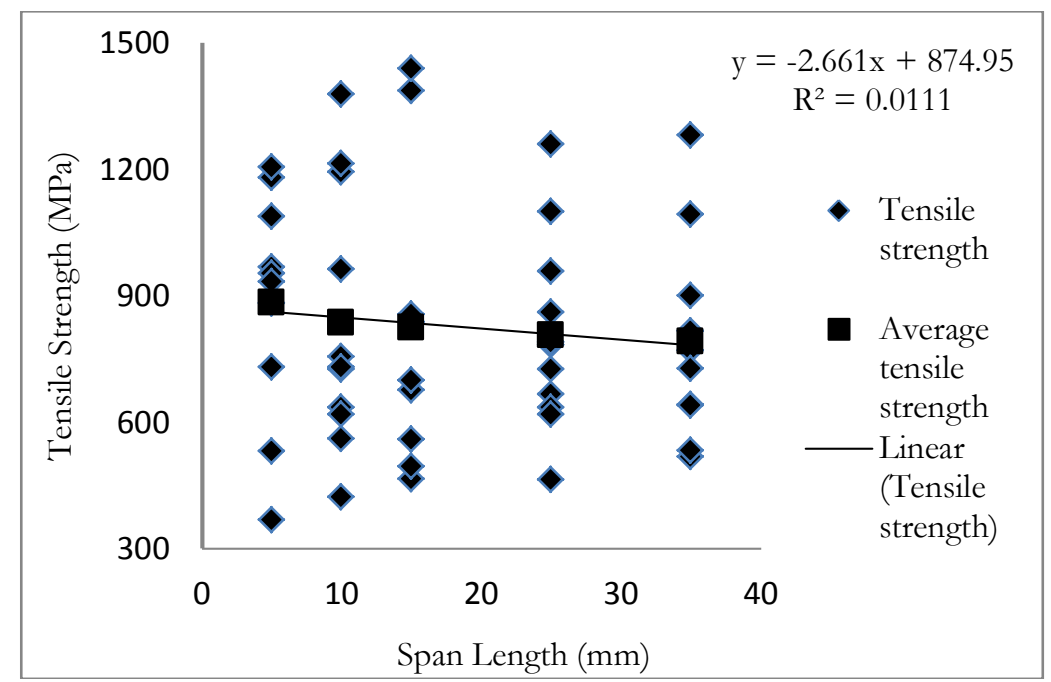

Fig. 3. Tensile strength as a function of fiber span length. 


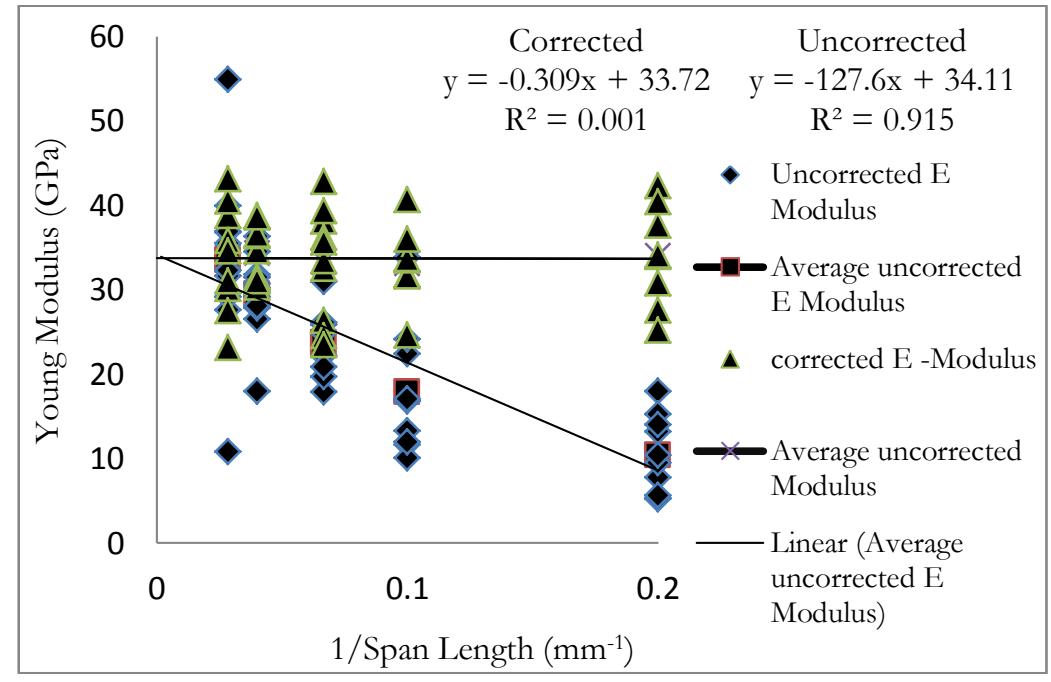

Fig. 4. Uncorrected and corrected Young's modulus versus span length.

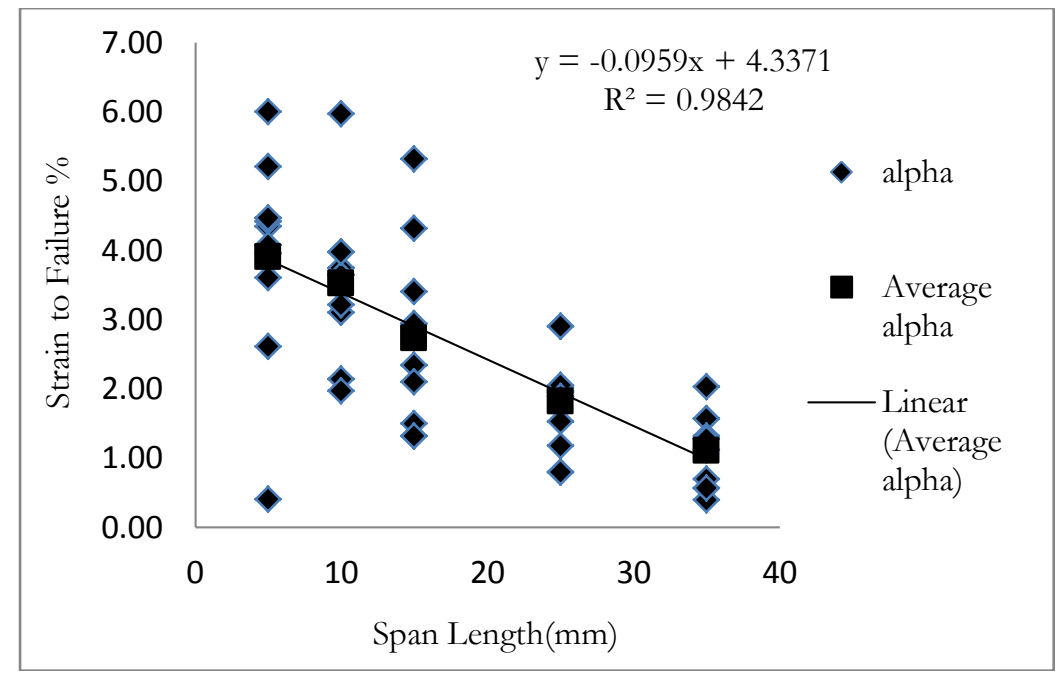

Fig. 5. Strain to failure as a function of span length.

From SEM, it was observed that the anatomical features directly affect physical and mechanical properties of bamboo. To understand the properties, it is important to study its anatomical characteristics. In circular cross section most bamboos are hollow. Bamboo culm comprises about $40 \%$ fibers. Fiber percentage is higher, which contributed to its superior slenderness and strength. Most fibers have a thick poly-lamellate secondary wall. Fibers in bamboos are either grouped in bundles or sheaths around the vascular bundle. This gives the high tensile strength to the bamboo fiber. For that, tensile strength of different span length fiber was measured. It was found that tensile strength decreased with increasing the fiber span length due to multicellular structural flaws, which broke the fiber easily. Uncorrected Young's modulus was dependent on span length. As Young's modulus should be independent of span length, a correction for Young's modulus values was conducted. After calculation it was found that modulus was independent of span length. Under SEM, it was observed that bamboo fiber is a technical fiber. When force was applied during tensile strength determination, the longitudinal fibers beared the load individually. As a result if one fiber failed, the other fiber beared the load. For that high tensile strength was observed. From the cross-sectional of bamboo block from SEM, sclerenchyma and parenchyma cell was observed, which beared the load applied to the fiber [18]. The ground tissue consists of parenchyma cells, which were mostly vertically elongated with short, cube-like inter-spread in between. The former is characterized by thicker walls with a polylamellate structure. In longitudinal direction, tensile strength and Young's modulus was dependent on the cell wall, which was assumed to positively correlate to the content of cellulose and 
lignin. From this study it can be concluded that chemical composition, anatomy are correlated to tensile strength.

\section{Conclusions}

For making composite with light weight reinforcement bamboo fiber can play a vital role depending on the mechanical properties available. Very positive results were found in present result conducted on single bamboo fiber. The sclerenchyma cell played dominant role on cell properties of meso bamboo. This may be due to the interactions between the components in bamboo where parenchymatous ground tissue passed loads and distributed the stress loaded on the fiber. It can be concluded that the unique structure of bamboo reflected that optimization of nature selection in accordance with the principal of most efficiency with least materials.

\section{References}

[1] R. A. Khan, A. J. Parsons, and I. A. Jones, G. S. Walker, and C. D. Rudd, "Preparation and characterization of phosphate glass fibers and fabrication of poly (caprolactone) matrix resorbable composites," J. Reinf. Plast. Compos., vol. 29, no. 12, pp. 1838-1850, 2010.

[2] R. A. Khan, M. A. Khan, H. U. Zaman, S. Pervin, N. Khan, S. Sultana, M. Saha, and A. I. Mustafa, "Comparative studies of mechanical and interfacial properties between jute and E-glass fiberreinforced polypropylene composites," J. Reinf. Plast. Compos., vol. 29, no. 7, pp. 1078-1088, 2010.

[3] J. P. Patel, N. M. Mehta, and P. H. Parsania, "Preparation and physico-chemical study of sandwich glass-jute-bisphenol-c-formaldehyde resin composites," Polym. Plast. Technol. Eng., vol. 49, no. 8, pp. 822-826, 2010.

[4] G. Sarkhel, B. Aswini, and A. Banerjee, "High-density polyethylene-ethylene propylene rubber-based thermoplastic elastomer: A mechanical modeling, thermal and rheological study," Polym. Plast. Technol. Eng., vol. 49, no. 10, pp. 1049-1054, 2010.

[5] S. B. Koradiya, , J. P. Patel, and P. H. Parsania, "The preparation and physic-chemical study of glass, jute and hybrid glass-jute bisphenol-c-based epoxy resin composites," Polym. Plast. Technol. Eng., vol. 49, no. 14, pp. 1445-1449, 2010.

[6] M. Jacob, S. Thomas, and K. T. Varughese, "Mechanical properties of sisal/oil palm hybrid fiber reinforced natural rubber composite," Compos. Sci. Technol., vol. 64, pp. 955-965, 2004.

[7] M. A. Khan, J. M. M. Islam, M. A. Rahman, R. A. Khan, and T. Islam, "Study on the effect of urea on the mechanical and morphological properties of jute/gelatin composites," Polym. Plast. Technol. Eng., vol. 49, no. 9, pp. 885- 891, 2010.

[8] M. Fan, "Chracterization and performance of hemp fibers: Factors influencing tensile strength," BioResources, vol. 5, no. 4, pp. 2307-2322, 2010.

[9] J. Li, S. Li, H. Wang, Y. Yang, and G. Guo, "Preparation of lignin based composite and its preparation," BioResources, vol. 6, no. 2, pp. 1532-1542, 2011.

[10] K. Dey, N. Sharmin, R. A. Khan, S. Nahar, A. J. Parsons, and C. D. Rudd, "Effect of iron phosphate glass on the physico-mechanical properties of jute fabric-reinforced polypropylene-based composites," J. Thermoplast. Compos. Mater., vol. 24, no. 5, pp. 695-711, 2011.

[11] X. Chen, Q. Guo, Y. Mi, "Bamboo fiber-reinforced polypropylene composites: A study of the mechanical properties," J. Appl. Polym. Sci., vol. 69, pp. 1891-1899, 1998.

[12] E. Trujillo, L. Osorio, A. W. Van Vuure, J. Ivens, and I. Verpoest, "Characterization of polymer composite materials based on bamboo fibers," 14th European Conference on Composite Materials, June 7-10, 2010, Budapest, Hungary, pp. 1-10.

[13] A. L. Duigou, P. Davies, and C. Baley, "Interfacial bonding of Flax fiber/Poly(l-lactide) biocomposites," Compos. Sci. Technol., vol. 70, no. 2, pp. 231-239, 2010.

[14] M. Das, and D. Chakraborty, "Influence of alkali treatment on the fine structure and morphology of bamboo fibers," J. Appl. Polym. Sci., vol.102, pp. 5050-5056, 2006.

[15] P. K. Kushwaha, and R. Kumar, "Studies on water absorption of bamboo-epoxy composites: effect of silane treatment of mercerized bamboo," J. Appl. Polym. Sci., vol. 115, pp. 1846-1852, 2010. 
[16] S. K. Chattopadhyay, R. K. Khandal, R. Uppaluri, and A. K. Ghoshal, "Bamboo fiber reinforced polypropylene composites and their mechanical, thermal, and morphological properties," J. Appl. Polym. Sci., vol. 119, pp. 1619-1626, 2011.

[17] M. Ahmad, and F. A. Kamke, "Analysis of calcutta bamboo for structural composite materials: Physical and mechanical properties," Wood Sci. Technol., vol. 39, pp. 448-459, 2005.

[18] Z. P. Shao, C. H. Fang, S. X. Huang, and G. L. Tian, "Tensile properties of Moso bamboo (Phyllostachys pubescens) and its components with respect to its fiber-reinforced composite structure," Wood Sci. Technol., vol. 44, pp. 655-666, 2010.

[19] T $210 \mathrm{~cm}-93$, "Sampling and testing of wood pulp shipments and testing wood pulp shipments for moisture, TAPPI, USA, 1993.

[20] ASTM D 1110-56, "Standard test method for water solubility of wood," USA, 1993.

[21] ASTM D 1106-56, "Standard test method for acid insoluble lignin in wood," USA, 1996.

[22] ASTM D 1104-56, "Method of test for holocellulose in wood," USA, 1978.

[23] ASTM D 1103-60, "Standard test method for $\alpha$-cellulose," USA, 1978.

[24] ASTM D 1102-84, "Standard test method for ash in wood," USA, 2001.

[25] N. Defoirdt, S. Biswas, L. De Vriese, Le Q. N. Tran, J. Van Acker, Q. Ahsan, L. Gorbatikh, A. Van Vuure, and I. Verpoest, "Assessment of the tensile properties of coir, bamboo and jute fiber," Composites Part $A$, vol. 41, no. 5, pp. 588-595, 2010.

[26] X. Li, "Physical, chemical and mechanical properties of bamboo and its utilization potential for bamboo boa manufacturing," Master of Science Thesis, Louisiana State University, USA, 2004.

[27] M. M. Thwe, and K. Liao, "Durability of bamboo-glass fiber reinforced polymer matrix hybrid composites," Compos. Sci. Technol., vol. 63, pp. 375-387, 2003.

[28] K. Okubo, T. Fujii, and Y. Yamamoto, "Development of bamboo-based polymer composites and their mechanical properties," Composites Part A, vol. 35, pp. 377-383, 2004.

[29] S.-X. Jiang, Q.-S. Zhang, and S.-H. Jiang, "On structure, production, market of bamboo-based panels in China," J. Forestry Research, vol. 13, no. 2, pp. 151-156, 2002.

[30] G. Siqueira, J. Bras and A. Dufresne, "Cellulosic bionanocomposite: A review of preparation, properties and application,” Polymer, vol. 2, pp. 728-765, 2010. 